\title{
AROMATASE AND NEUROREGENERATION
}

\author{
Zulvikar Syambani Ulhaq ${ }^{1}$ \\ Correspondence: zulvikarsyambaniulhaq@yahoo.com \\ ${ }^{1}$ Graduate School of Science and Technology Kumamoto University, Japan.
}

\section{Article History}

Received: August 17, 2018

Accepted: December 14, 2018

Published: January 1, 2019

\section{Cite this as:}

Ulhaq, ZS. Aromatase and neuroregeneration. Malang Neurology Journal; 2019.5:4850. DOI:

http://dx.doi.org/10.21776/ub.mnj .2019 .005 .01 .9

\section{ABSTRACT}

Aromatase (cyp19al) is a converting enzyme for estrogen biosynthesis. A single gene of cyp19al identified in mammals and specific promoter differentially regulates $E_{2}$ produce in the brain. Interestingly, teleost fish having two isoforms of cyp19a1, cyp19ala and cyl9alb, encoding ovarian and brain aromatase, respectively. In addition, teleost fish are characterized by having highly aromatase activity and neuroregenerative response. In contrast with fish, neuroregeneration process is limited in mammals. Therefore, understanding molecular mechanism of estradiol signaling in neural injury in fish may give a new insight for the development of novel treatment in mammals, particularly in neurodegenerative diseases. Here, the author briefly reviews and discusses the potential role of neural estrogen for regeneration process.

Keywords: Aromatase, regeneration, teleost

\section{Introduction}

Estrogen is catalyzed from testosterone by aromatase enzyme. ${ }^{1}$ It is widely known the action of estrogen on reproductive system. ${ }^{2}$ However, it has been reported that estrogen receptor (ER) is highly expressed across the brain area during development, ${ }^{3,4}$ indicating the role of estrogen for brain development. Several line of evidences show that estradiol $\left(\mathrm{E}_{2}\right)$ is de novo catalyzed in the brain, ${ }^{5}$ suggesting $\mathrm{E}_{2}$ is locally produced in the brain. Though it is difficult to distinguish the source of $\mathrm{E}_{2}$ production to understand the role of brain estrogen in mammals, several approaches technique used to elucidate the role of brain estrogen, such as aromatase knock out (KO), ${ }^{6}$ Yet, the function of estrogen produced in the brain is not completely understood.

Teleost fish, including zebrafish, characterized by having two aromatase (cyp19al) isoforms, cyp19ala and cyp19alb expressed predominantly in ovary and brain, respectively ${ }^{7}$. Moreover, brain aromatase (AroB) is highly expressed in early development, ${ }^{7}$ suggesting the important of brain estrogen for brain development. Furthermore, zebrafish showing high neurogenic activity in the brain compared with mammals, ${ }^{8}$ implying a close relationship between aromatase and neurogenesis. Recent study indicate that AroB regulates serotonergic neuron in embryonic zebrafish, which possibly one of the mechanisms of AroB in modulating brain neurogenesis, ${ }^{9}$ Thus, zebrafish makes a good model to understand the role of brain estrogen.

\section{Glial Aromatization}

In mammals, aromatase is expressed in glia and neuronal cells in the brain. ${ }^{10}$ Interestingly, AroB expression is restricted to radial glial cells (RGCs) in zebrafish, acting as neural progenitor. ${ }^{11}$ To evaluate the role of brain aromatase in neuroregeneration, several studies performed brain injury. Following brain injury, aromatase level is increase and starts to express in the astrocyte. ${ }^{12-14}$ Indeed, aromatase is exhibited proliferative activity in RGCs. ${ }^{15}$ Similar to that observed in mammals, induction of $\mathrm{AroB}^{+} \mathrm{RGCs}$ in fish concurrence with the increase of proliferating cell nuclear antigen $\left(\mathrm{PCNA}^{+}\right)$cells. ${ }^{16}$ These results support that upregulation of $\mathrm{E}_{2}$ biosynthesis is necessary as a response to neural injury, possibly to promote regeneration and repair.

Spinal cord is a part of central nervous system. Recent study showed that zebrafish connective tissue growth factor a (ctgfa) together with radial glia accelerated the bridging process in spinal cord injury. ${ }^{23}$ Aromatase expressions are known shifted from neuron to reactive astrocyte and might exerts its neuroprotective effect in the end stage of amyotrophic lateral sclerosis (ALS). ${ }^{24}$ Indeed, the inflammatory mediators stimulate the activation of cyp19al gene during neural injury (Fig. 1) ${ }^{18}$ and AroB is expressed in fish spinal cord. ${ }^{16}$ Hence, it is possible to hypothesize that AroB radial glia of spinal cord might be contributes as one of the important factors in stimulating neural regeneration. Furthermore, several evidences indicates that additional of $E_{2}$ speed up the recovery time in spinal cord injury. $^{25,26}$ Taken together, this review emphasized the importance of brain-formed estrogen for neural regeneration and repair. Thus, $E_{2}$ might be useful as treatment for neurodegenerative diseases in mammals.

\section{Conclusion}

Highly expression of brain aromatase and neuroregenerative capability in fish makes a zebrafish a useful model for evaluating the function of brain aromatase in neurogenesis. Estradiol produce in the brain is involved in regulating brain repair and plasticity in fish. 


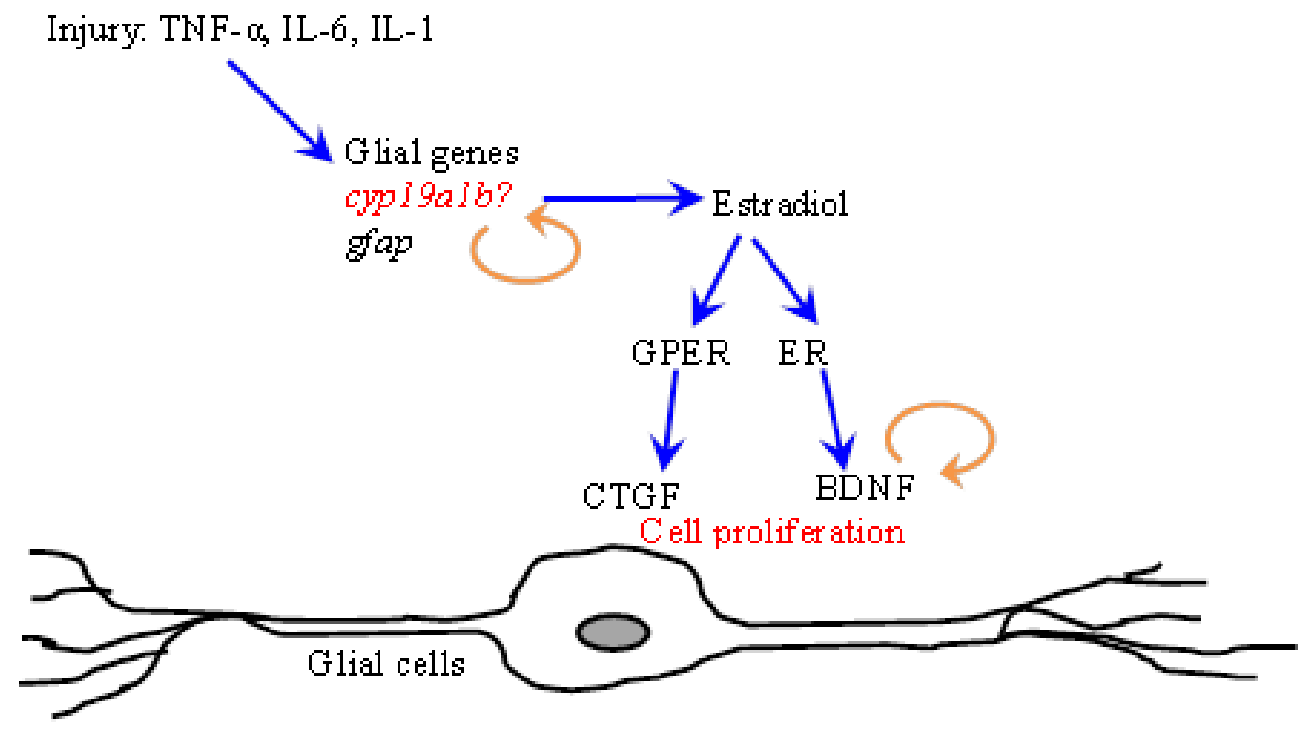

Figure 1. Possible mechanism of aromatase induces spinal cord regeneration. Pro-inflammatory mediators induce the upregulation of cyp19a1b and gfap in glial cells17-19. As a result, there is an increase of E2 biosynthesis by the activation of AroB, and create a positive loop between E2-AroB. Through genomic (nuclear ER) signaling, E2 stimulate brain-derived neurotrophic factor (BDNF), a neurotropic factor, to promote cell proliferation20. Interestingly, BDNF auto-regulation bring a positive feedback loop to increase its production, indicating that this mechanism is important to obtain BDNF levels in modulating physiological outcome in neuron21. In addition to genomic action, it is well established that non-genomic (membrane ER, GPER/GPR30) signaling is important for rapid action of E2 in the brain. Binding of E2-GPER initiates the activation of ctgf gene to further stimulates cell proliferation22, which possibly speed up neural repair in fish.

\section{References}

1. Garringer JA, Niyonkuru C, McCullough EH, Loucks $\mathrm{T}$, Dixon CE, Conley YP, Berga S, Wagner AK. Impact of aromatase genetic variation on hormone levels and global outcome after severe TBI. J Neurotrauma; 2013.30(16):1415-25. DOI: 10.1089/neu.2012.2565

2. Findlay JK, Liew SH, Simpson ER, Korach KS. Estrogen signaling in the regulation of female reproductive functions. Handb Exp Pharmacol; 2010.198:29-35. DOI: 10.1007/978-3-642-02062-9_2

3. Gonzales KL, Quadros-Mennella P, Tetel MJ, Wagner CK. Anatomically-specific actions of oestrogen receptor in the developing female rat brain: effects of oestradiol and selective oestrogen receptor modulators on progestin receptor expression. J Neuroendocrinol; 2012.24(2):285-91.

DOI:

$10.1111 / \mathrm{j} .1365$ 2826.2011.02232.x

4. Wilson ME, Westberry JM, Trout AL. Estrogen receptor-alpha gene expression in the cortex: sex differences during development and in adulthood. Horm Behav; 2011.59(3):353-7. DOI: 10.1016/j.yhbeh.2010.08.004

5. Yamazaki T, Yamamoto M, Ishihara Y, Komatsu S, Munetsuna E, Onizaki M, Ishida A, Kawato $\mathrm{S}$, Mukuda T. De novo synthesized estradiol protects against methylmercury-induced neurotoxicity in cultured rat hippocampal slices. PLoS One; 2013.8(2):e55559.

DOI:

10.1371/journal.pone.0055559

6. Bakker J, Honda S, Harada N, Balthazart J. The aromatase knockout (ArKO) mouse provides new evidence that estrogens are required for the development of the female brain. Ann N Y Acad Sci;
2003.1007:251-62.

PubMed:

https://www.ncbi.nlm.nih.gov/pubmed/14993058

7. Kishida M, Callard GV. Distinct cytochrome P450 aromatase isoforms in zebrafish (Danio rerio) brain and ovary are differentially programmed and estrogen regulated during early development. Endocrinology; 2001.142(2):740-50. DOI: 10.1210/endo.142.2.7928

8. Zupanc GK. Adult neurogenesis and neuronal regeneration in the brain of teleost fish. J Physiol Paris; 2008.102(4-6):357-73. DOI: 10.1016/j.jphysparis.2008.10.007

9. Ulhaq ZS, Kishida M. Brain aromatase modulates serotonergic neuron by regulating serotonin levels in zebrafish embryos and larvae. Front. Endocrinol; 2018.9:230. DOI: 10.3389/fendo.2018.00230

10. Yague JG, Muñoz A, de Monasterio-Schrader P, Defelipe J, Garcia-Segura LM, Azcoitia I. Aromatase expression in the human temporal cortex. Neuroscience; 2006.138(2):389-401. DOI: 10.1016/j.neuroscience.2005.11.054

11. Menuet A, Pellegrini E, Brion F, Gueguen MM, Anglade I, Pakdel F, Kah O. Expression and estrogen-dependent regulation of the zebrafish brain aromatase gene. J Comp Neurol; 2005. 485(4):304-20

12. Garcia-Segura LM, Wozniak A, Azcoitia I, Rodriguez JR, Hutchison RE, Hutchison JB. Aromatase expression by astrocytes after brain injury: implications for local estrogen formation in brain repair. Neuroscience; 1999.89:567-578. DOI: 10.1016/S0306-4522(98)00340-6

13. Duncan KA, Saldanha CJ. Neuroinflammation induces glial aromatase expression in the uninjured songbird brain. J Neuroinflammation; 2011.8:81. DOI: 10.1186/1742-2094-8-81

14. Gatson JW, Simpkins JW, Yi KD, Idris AH, Minei JP, Wigginton JG. Aromatase is increased in 
astrocytes in the presence of elevated pressure. Endocrinology; 2011.152(1):207-13. DOI: 10.1210/en.2010-0724

15. Jeng SR, Yueh WS, Pen YT, Gueguen MM, Pasquier J, Dufour S, Chang CF, Kah O. Expression of aromatase in radial glial cells in the brain of the Japanese eel provides insight into the evolution of the cyp191a gene in Actinopterygians. PLoS One; 2012.7(9):e44750.

DOI: 10.1371/journal.pone.0044750

16. Diotel N, Le Page Y, Mouriec K, Tong SK, Pellegrini E, Vaillant C, Anglade I, Brion F, Pakdel F, Chung BC, Kah O. Aromatase in the brain of teleost fish: expression, regulation and putative functions. Front Neuroendocrinol; 2010.31(2):172-92. DOI: 10.1016/j.yfrne.2010.01.003

17. Zhao Y, Nichols JE, Valdez R, Mendelson CR, Simpson ER. Tumor necrosis factor-alpha stimulates aromatase gene expression in human adipose stromal cells through use of an activating protein-1 binding site upstream of promoter 1.4. Mol Endocrinol; $\quad$ 1996.10(11):1350-7. DOI: 10.1210/mend.10.11.8923461

18. Duncan KA, Saldanha CJ. Neuroinflammation induces glial aromatase expression in the uninjured songbird brain. J Neuroinflammation; 2011.8:81. DOI: 10.1186/1742-2094-8-81

19. Li D, Liu N, Zhao HH, Zhang X, Kawano H, Liu L, Zhao L, Li HP. Interactions between Sirt1 and MAPKs regulate astrocyte activation induced by brain injury in vitro and in vivo. J Neuroinflammation; 2017.14(1):67. DOI: 10.1186/s12974-017-0841-6

20. Dong F, Zhang Q, Kong W, Chen J, Ma J, Wang L, Wang Y, Liu Y, Li Y, Wen J. Regulation of endometrial cell proliferation by estrogen-induced BDNF signaling pathway. Gynecol Endocrinol; 2017.33(6):485-489. 10.1080/09513590.2017.1295439

DOI:

21. Tuvikene J, Pruunsild P, Orav E, Esvald EE, Timmusk T. AP-1 Transcription Factors Mediate BDNFPositive Feedback Loop in Cortical Neurons. J Neurosci; 2016.36(4):1290-305. DOI: 10.1523/JNEUROSCI.3360-15.2016

22. Pandey DP, Lappano R, Albanito L, Madeo A, Maggiolini M, Picard D. Estrogenic GPR30 signalling induces proliferation and migration of breast cancer cells through CTGF. EMBO J; 2009.28(5):523-32. DOI: 10.1038/emboj.2008.304

23. Mokalled MH, Patra C, Dickson AL, Endo T, Stainier DY, Poss KD. Injury-induced ctgfa directs glial bridging and spinal cord regeneration in zebrafish. Science; 2016.354(6312):630-634. DOI: 10.1126/science.aaf2679

24. Sun C, Liu Y, Liu Y, Zhao M, Zhai J, Hao P, Wang $\mathrm{Y}, \mathrm{Ji}$ Y. Characterization of aromatase expression in the spinal cord of an animal model of familial ALS. Brain Res Bull; 2017.6;132:180-189. DOI: 10.1016/j.brainresbull.2017.05.016

25. Sengelaub DR, Han Q, Liu NK, Maczuga MA, Szalavari V, Valencia SA, Xu XM. Protective effects of estradiol and dihydrotestosterone following spinal cord injury. J Neurotrauma; 2018.35(6):825841. DOI: 10.1089/neu.2017.5329

26. Sribnick EA, Samantaray S, Das A, Smith J, Matzelle DD, Ray SK, Banik NL. Postinjury estrogen treatment of chronic spinal cord injury improves locomotor function in rats. J Neurosci Res; 2010.88(8):1738-50. DOI: $10.1002 /$ jnr.22337 